\title{
Laser Cryo Enrichment
}

National Cancer Institute

\section{Source}

National Cancer Institute. Laser Cryo Enrichment. NCI Thesaurus. Code C97316.

A technology that allows for high-throughput laser dissection of frozen specimens.

Reference slides are cut and are used to determine regions that should be retained. After review of the reference slide by a pathologist, tissues are robotically dissected in large groups. The main tissue block remains unchanged and is not chemically treated or thawed, which allows for extraction and analysis of high quality DNA, RNA, or protein. 